$$
\text { CONF- } 960723--4
$$

ERNEST DRLANDO LAWRENCE BERKELEY NATIONAL LABDRATIRY

\title{
Vacuum-Spark Metal Ion Source Based on a Modified Marx Generator
}
A. Anders, I.G. Brown, R.G. MacGill, and M.R. Dickinson

\section{Accelerator and Fusion \\ Research Division}

\section{April 1996}

To be presented at the XVIItb International Symposium on Discharges and Electrical Insulation in Vacuum (ISDEIV), Berkeley, CA, July 21-26, 1996, and to be published in the Proceedings 


\section{DISCLAIMER}

This document was prepared as an account of work sponsored by the United States Government. While this document is believed to contain correct information, neither the United States Government nor any agency thereof, nor The Regents of the University of California, nor any of their employees, makes any warranty, express or implied, or assumes any legal responsibility for the accuracy, completeness, or usefulness of any information, apparatus, product, or process disclosed, or represents that its use would not infringe privately owned rights. Reference herein to any specific commercial product, process, or service by its trade name, trademark, manufacturer, or otherwise, does not necessarily constitute or imply its endorsement, recommendation, or favoring by the United States Government or any agency thereof, or The Regents of the University of California. The views and opinions of authors expressed herein do not necessarily state or reflect those of the United States Government or any agency thereof, or The Regents of the University of California.

Ernest Oriando Lawrence Berkeley National Laboratory is an equal opportunity employer. 


\section{DISCLAIMER}

Portions of this document may be illegible in electronic image products. Images are produced from the best available original document. 
XVIIth International Symposium on

Discharges and Electrical Insulation in Vacuum (ISDEIV)

Berkeley, July 21-26, 1996

\title{
VACUUM-SPARK METAL ION SOURCE BASED ON A MODIFIED MARX GENERATOR
}

\author{
André Anders, Ian G. Brown, Robert A. MacGill, and Michael R.
} Dickinson

Lawrence Berkeley National Laboratory, University of California, Berkeley, CA 94720

April 1996

This work was supported by the U.S. Department of Energy, Division of Advanced Energy Projects, under contract No. DE-AC03-76SF00098. 


\title{
VACUUM-SPARK METAL ION SOURCE BASED ON A MODIFIED MARX GENERATOR
}

\author{
André Anders, Ian G. Brown, Robert A. MacGill, and Michael R. Dickinson \\ Lawrence Berkeley National Laboratory, University of California, Berkeley, CA 94720
}

\begin{abstract}
The plasma generating parts of ion sources including their power supplies are usually floated to high potential (ion extraction voltage), thus requiring great insulation efforts and high costs for high-energy ion beams. A new concept for pulsed ion sources is presented in which a single power supply is used to simultaneously produce the plasma and high extractor voltage via a modified Marx generator. Proof-ofprinciple experiments have been performed with highcurrent spark discharges in vacuum where multiply charged ions are produced with this Marx-generator based ion source ("Magis"). Using "Magis", it has been demonstrated that pulsed ion beams of very high energies can be obtained with relatively low voltage. For copper, ion of charge states up to $7+$ have been found whose energy was $112 \mathrm{keV}$ for a charging voltage of only $10 \mathrm{kV}$.
\end{abstract}

\section{INTRODUCTION}

The production of ion beams is generally done in two steps: (i) the material of interest is ionized so that ions form a plasma with free electrons and neutrals, and (ii) the ions are extracted from the plasma, commonly by using a three-grid system of the accel-decel type. Examples for step (i) are Penning, DC magnetron, hot cathode filament or RF gas discharges, or arc discharges in vacuum. Step (ii) requires that the plasma potential is much higher than the potential of the beam and substrate, allowing the ions to become accelerated by the potential difference (extraction voltage). Therefore, the plasma-generating parts of an ion sources including its plasma power supplies are floated to high positive potential (or negative for negative ions). Ion sources have consequently at least two power supplies: one at elevated potential producing the plasma, and a second which floats the first together with the extractor system to the elevated potential. Insulation requirements for high ion energies (hundreds of $\mathrm{keV}$ or higher) imply substantial difficulties and costs. In this paper we report about the concept and proof-ofprinciple experiments showing that a single, non- floating power supply can be used to produce a plasma at elevated potential.

Another basic idea presented in this paper is to increase the ion charge state in the plasma prior to extraction to obtain high ion energy at relatively low extraction voltage. The pulsed system serving for both plasma production and ion extraction is well suited to obtain a high energy density in the plasma resulting in multiply charged ions. As an example we investigated repetitively pulsed, high-current discharges between metal electrodes in vacuum (vacuum sparks). High charge states have been observed spectroscopically in vacuum sparks. At very high currents (greater than $100 \mathrm{kA}$ ) and discharge energies (greater than $3 \mathrm{~kJ}$ ), extremely high charge states such as $\mathrm{H}$-like and $\mathrm{He}$-like $\mathrm{Ti}$ and $\mathrm{Fe}$ have been observed in "hot spots" (see, for instance, [1-3]). These hot spots have a lifetime in the sub-nanosecond range, and there is no hope to extract these extremely charged ions to form an ion beam. A realistic goal, however, is to extract ions whose charge state is significantly higher than what is usually obtained in metal vapor vacuum arc (Mevva) ion sources. This is important because a gain in charge state leads to a proportionally higher ion energy for a given extraction voltage.

\section{CONCEPT OF A MARX- GENERATOR BASED ION SOURCE ("MAGIS")}

A Marx generator is a voltage-multiplying scheme proposed decades ago [4]. The idea is to charge capacitors $C_{i}(i=1,2, \ldots, N)$ for a voltage $U_{o}$ and switch them in series to obtain a high voltage

$$
U_{\max }=N U_{o}
$$

Equation (1) neglects losses; the number $N$ should in practice not exceed 10 [5]. We describe the standard Marx generator (Fig. 1) in more detail because it helps understanding the modified scheme of the ion source. 


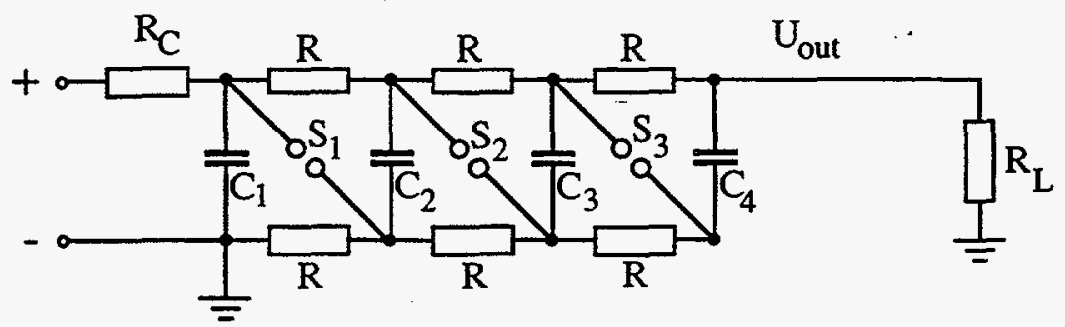

Fig. 1 Schematic of a four stage Marx generator; $R_{C}$ : charging resistor; $R$ : stage-separating resistors; $\mathrm{C}_{\mathrm{i}}$ : capacitors, $\mathrm{S}_{\mathrm{i}}$ switches (spark gaps); $\mathrm{U}_{\text {out }}$ : output voltage; $\mathrm{R}_{\mathrm{L}}$ : load

During charging, all $N$ capacitors are electrically in parallel with one side at ground potential. It is important to note that all but the first capacitor are mounted insulated from ground and that all capacitors are separated from each other by resistors. There is a switch $S_{i}$ between the high potential side of capacitor $C_{i}$ and the ground of capacitor $C_{i+1}$, with the counting index $i=1,2, \ldots, N-1$. For high voltage applications, as in our case, spark gaps are commonly used as switches. Switch $S_{1}$ is triggered or set to break down first. The ground of $C_{2}$ shifts to the potential $U_{o}$ and its high potential side to $2 U_{o}$, causing an overpotential of $2 U_{o}$ at spark gap $S_{2}$. Consequently, $S_{2}$ breaks down shifting the ground potential of $C_{3}$ to $2 U_{o}$ and its high potential side to $3 U_{o}$, etc.

A novel Marx-generator-like scheme has been employed to generate a discharge plasma at elevated potential, thus allowing simultaneous plasma production and ion extraction. The principle of this Marx-generator based ion source, "Magis", is explained for the case when four Marx generator stages are used (Fig. 2).

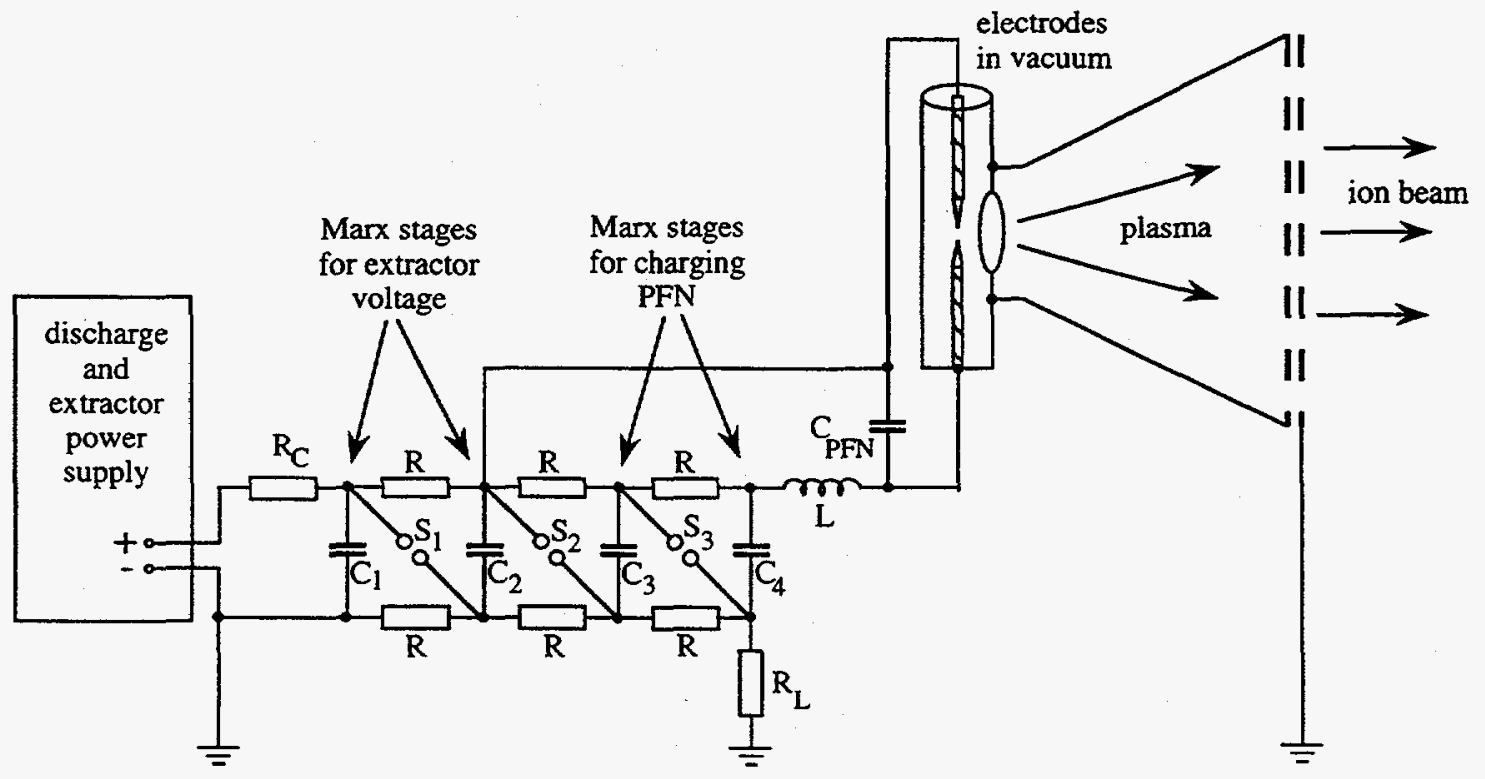

Fig. 2 Principal electrical scheme of "Magis". The pulse forming network is symbolically represented by a lumped capacitor, $C_{P F N} ; \mathrm{L}$ - inductive resistor (coil); the other notation is as in Fig. 1. 
The two stages near the ground potential are exclusively used to shift the potential of the plasma by $2 U_{0}$ above ground. The main function of the other two stages is to charge the capacitors of the pulse forming network (PFN). The PFN represents the energy source for the discharge plasma. It can consist of discrete $L C$ stages or a coaxial cable, or strip line, etc.

The operation of "Magis" starts with charging of all capacitors via a charging resistor, $R_{c}$. The spark gaps are set in such a way that gap 2 breaks down first, causing all other spark gaps to trigger. After breakdown of spark gap 3 and 4 , the energy stored in $C_{3}$ and $C_{4}$ is transferred to the PFN via the inductive load $L$. The voltage at the PFN is given by (neglecting Ohmic losses)

$$
U_{P F N}(t)=U_{o} \frac{C_{M}}{C_{M}+C_{P F N}}\left[1-\cos \left(t / \sqrt{L_{c} C_{c}}\right)\right]
$$

where $C_{M}$ is the series capacitance of the Marx capacitors used for charging the PFN, $C_{c}=\frac{C_{P F N} \cdot C_{M}}{C_{P F N}+C_{M}}$, and $L_{c}$ is the inductance of the circuit. The charging of the PFN is terminated when a discharge starts in the discharge chamber (the discharge is a vacuum spark in our case).

Another function of the last two stages is to boost the plasma potential beyond the $2 U_{0}$ coming from the first two stages of the Marx generator. The plasma potential is related to the potential of the electrodes; because they have approximately the potential $2 U_{o}$ and $4 U_{o}$, the plasma potential is in between these values. Its actual value depends on the plasma and the discharge circuit. Ideally, the PFN is terminated with an impedance-matching resistor, thus avoiding undesired oscillations of the discharge current and the associated plasma potential.

\section{PROOF-OF-PRINCIPLE EXPERIMENTS}

A "Magis" has been built following the principles described above. As plasma we used a high current discharge in vacuum. The vacuum discharge was driven by either a simple high-voltage capacitor or by a 6-stage PFN made from lumped elements (high-voltage capacitors and inductors); in both cases the charging was done by a Marx-generator-like scheme as shown in Fig. 2. Another experiment is in preparation using a low-impedance high-voltage cable as the PFN. The maximum charging voltage was $U_{0}=15 \mathrm{kV}$. In our preliminary tests we sacrificed the matching termination of the PFN in order to obtain high currents at relatively high impedance and relatively low voltage. First test were made with a simple capacitor as the "PFN". This capacitor formed an $L C$ circuit with the inductance of the electrodes and their connecting cables. This has the advantage that a high peak current can easily be achieved. The discharge current oscillates with-a damping depending on the Ohmic resistance of the circuit including the discharge plasma. A disadvantage is that also the potential of the electrodes in the discharge chamber oscillates, i.e. the extractor voltage is time dependent in this case (Fig. 3a). This can be avoided by using a PFN with matched termination.

A high discharge current in vacuum (vacuum spark) produces a great amount of plasma. Although the dense plasma expands during its flight from the electrode region to the extractor grid system, its density at the grid was found to be too high for optimum extraction. One way of overcoming this problem is to increase the distance between the discharge electrodes (location of plasma production) and the extractor grids (location of ion extraction). A greater distance allows further plasma expansion until optimum extraction at the grid (perveance match condition) can be reached. It is educational to do the following order-of-magnitude estimate. Let's assume that the plasma expansion law for low-current vacuum arcs [6]

$$
n \approx \gamma I / r^{2}
$$

can be extrapolated to high currents ( $n$ is the plasma density $\left(\mathrm{m}^{-3}\right), \quad \gamma=10^{13} \mathrm{~A}^{-1} \mathrm{~m}^{-1}, I$ the discharge current (A), and $r$ the distance from the cathode spot (m)). It is known that optimum extraction for vacuum arc ion sources is typically obtained at about $n \approx 10^{17} \mathrm{~m}^{-3}(I=100 \mathrm{~A}$ and $r \approx 0.1 \mathrm{~m})$. Optimum extraction for a vacuum spark ion source is reached at $r \approx \sqrt{\gamma I / n} \approx 1 \mathrm{~m}$ for $10 \mathrm{kA}$. The diameter of the ion beam should be of the same order of magnitude to utilize a reasonable fraction of the amount of plasma available. A vacuum spark ion source is therefore inherently a very broad beam ion source. Going to smaller distances and diameters implies not only less efficient utilization of the plasma but creates breakdown problems at the extractor and makes extraction impossible: the dense plasma "flows" through the beamlet holes of the extractor and shorts them. Since we are interested only in proof-ofprinciple experiments, we have artificially reduced the plasma density by inserting two stainless steel meshes in the expansion zone between the electrodes and the extractor (total transparency about 0.1). An additional useful "trick" is to place a fine metal mesh onto the first extractor grid thus defining and stabilizing the plasma boundary [7]. This is 
particularly useful because the plasma density at the extractor is not constant in our experiment.

A typical result of our proof-of-principle experiments with copper electrodes is shown in Figures $3 a$ and $b$. Channel 1 shows the potential measured at the electrode which is connected to the first (plasma facing) extractor grid (= extractor voltage). The noise at the first division indicates the breakdown of the spark gaps of the Marx generator and the beginning of the charging of the final capacitor. The potential increases until the vacuum spark gap breaks down. This is the beginning of the oscillating discharge current. The TOF gate is set to investigate the plasma composition at a given time (the maximum of the fifth halfcycle in the example of Figs. $3 a$ and $b$ ). Fig. $3 b$ shows that the first ions arrive $600 \mathrm{~ns}$ after the gate pulse at the TOF detector which is a magnetically shielded Faraday cup, located $1.1 \mathrm{~m}$ downstream from the gating plates. These first ions are hydrogen; they originate together with oxygen and carbon from the lucite window which was at the time of these investigations placed close to the vacuum discharge gap. The slowest ions are iron ions which came from the plasma attenuator (SS meshes). Stainless steel contains mainly $\mathrm{Fe}$ (about $68 \%$ ), $\mathrm{Cr}$ (about 19\%) and Nickel (about 10\%). The $\mathrm{Fe}^{+}$line is likely to be slightly broadened by these other elements of similar mass. The lines of $\mathrm{Cu}^{7+}$ and $\mathrm{Cu}^{6+}$ are merged because they could not be resolved with the TOF spectrometer used. The maximum of the observed line is located where the $\mathrm{Cu}^{7+}$ ions are to be expected, and the $\mathrm{Cu}^{6+}$ ions cause an asymmetric shape of the line.

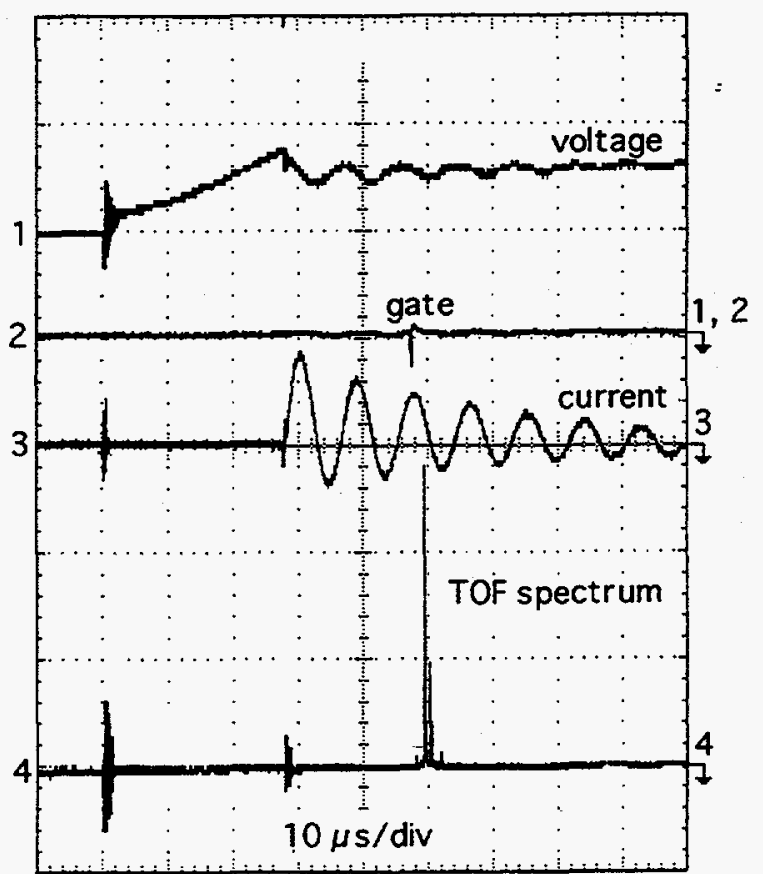

Figure 3a. Overview of a single discharge with copper electrodes in vacuum: 1: extractor voltage (10 $\mathrm{kV} / \mathrm{div})$; 2 : TOF gate potential $(10 \mathrm{kV} / \mathrm{div}) ; 3$ : discharge current $(5 \mathrm{kA} /$ div $)$, 4: TOF signal (20 $\mathrm{mV} / \mathrm{div}$ at $50 \Omega$ termination). The channel numbers 1-4 are shown on the left side for each curve while the numbers on the right side show the position of the ground potential for each channel.

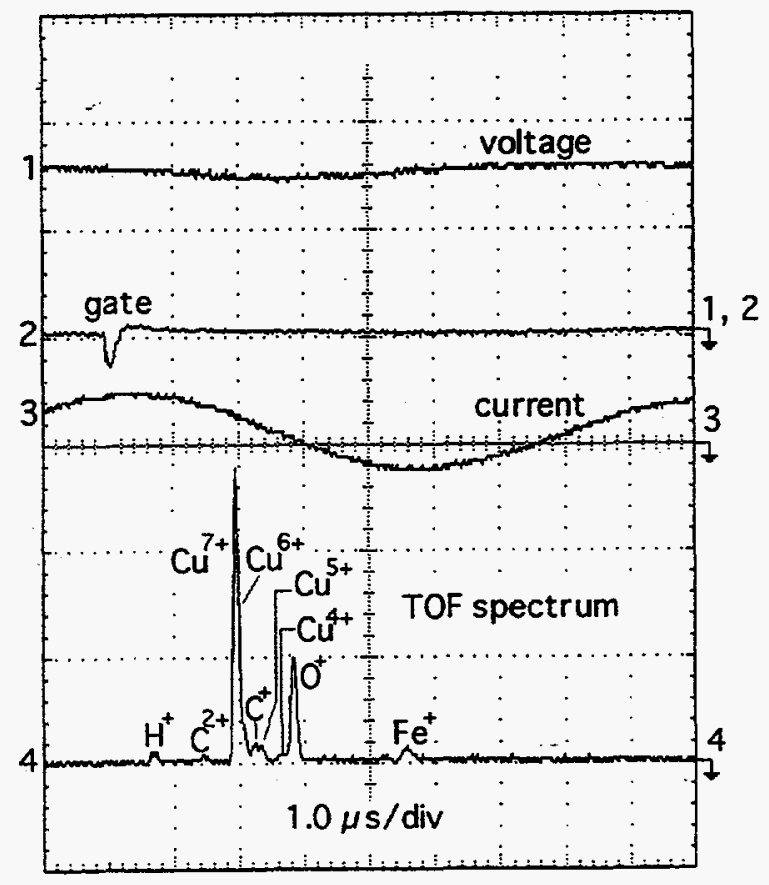

Figure 3b. Same discharge as shown in Fig. 3a but with higher time resolution revealing the details of the TOF spectrum which is discussed in the text. The higher time resolution was obtained by the Zoom Function of the digital storage oscilloscope TDS 744. 
The charging voltage in the example of Figure 3 was $10 \mathrm{kV}$ and the extractor voltage $16 \mathrm{kV}$ at the time of extraction of the ions under investigation. Since the highest ion charge state of copper was $7+$, the energy of these ions was $112 \mathrm{kV}$.

Measurements of the ion beam current have not been done because the present test system is not designed for optimum performance (about $99 \%$ of the plasma is not used for these proof-of-principle experiments). A new, very broad beam "Magis" ion implantation system is under development.

\section{OUTLOOK}

It has been shown that a pulsed ion source can be operated with a single power supply combined with a Marx-generator-like circuit; no floating power supplies are required. The principle can be applied to various pulsed ion sources but is particularly suited to an ion source utilizing a vacuum spark for plasma production. The number of Marx stages used for the extractor voltage versus the number used for plasma production can be adapted to the specific kind of source and energy range desired. The voltage can be scaled up to obtain ion beams of $\mathrm{MeV}$ energy using voltages smaller than $100 \mathrm{kV}$. Experiments with external pulsed magnetic fields indicate that the ion charge states can be further enhanced $[7,8]$ Problems such as shot-to-shot reproducibility, electrode erosion and replacement, enhanced duty factor (pulse repetition rate) and related power and cooling problems, and long-term stability have to be addressed in the future.

\section{ACKNOWLEDGMENTS}

One of us (A.A.) would like to acknowledge valuable discussions with $R$. Tkotz, formerly with the University of Erlangen, Germany. This work was supported by the U.S. Department of Energy, Division of Advanced Energy Projects, under contract No. DE-AC03-76SF00098.

\section{REFERENCES}

[1] K. N. Koshelev and N. R. Pereira, J. Appl. Phys. 69, R21-R44 (1991).

[2] C. R. Negus and N. J. Peacock, J. Phys. D: Appl. Phys., 12, 91-111 (1979).

[3] J. J. Turechek and H.-J. Kunze, Zeitschrift $f$. Physik A 273, 111-120 (1975).

[4] E. Marx, Elektrotechnische Zeitschrift 45, 652654 (1924).
[5] W. Pfeiffer, Impulstechnik. (Carl Hanser Verlag, München, 1976).

[6] B. Jüttner, J. Phys. D: Appl. Phys., 18, 22212231 (1985).

[7] E. Oks, A. Anders, I. G. Brown, M. R. Dickinson, and R. A. MacGill, submitted to IEEE Trans. Plasma Sci. (1996).

[8] E. Oks, A. Anders, I. Brown, M. Dickinson, and R. MacGill, these Proceedings. 